\title{
Making the cycling environment safer: an investigation based on hospital admissions
}

\section{Ben Ewalda,c and Tim Cowan ${ }^{b}$}

a University of Newcastle, School of Medicine and Public Health, NSW, Australia

b Hunter New England Health, Newcastle, NSW, Australia

c Corresponding author: ben.ewald@newcastle.edu.au

\section{Article history}

Publication date: July 2015

Citation: Ewald B, Cowan T. Making the cycling environment safer: an investigation based on hospital admissions. Public Health Res Pract. 2015;25(3):e2531535. doi: http:// dx.doi.org/10.17061/phrp2531535

\section{Introduction}

The physical activity benefits of urban cycling could make an important contribution to health ${ }^{1}$, but safety fears prevent many people from riding. ${ }^{2}$ Because only a minority of bike crashes are investigated by police, local governments receive little feedback about the safety of the roads and cycleways they manage. ${ }^{3}$ The NSW Bike Plan 2010 contains a target to increase the share of short trips taken by bike in greater Sydney to $5 \%$ by 2016. However, meeting this target would more than double the number of cycling trips and likely increase the number of injuries.

We set out to answer the following questions: can the incidence of bicycle injury crashes be measured at the local government area (LGA) level from hospital records? Is it feasible to interview people after hospital admission to understand bicycle crashes, and does this yield information about remediable hazards? Answering these questions may create a feedback loop from the health system to road authorities to make the cycling environment safer.

\section{Methods}

We searched records of John Hunter Hospital for crashes that occurred between 1 August 2012 and 31 July 2013. Records were searched for International Statistical Classification of Diseases and Related Health Problems, Tenth Revision, Australian Modification (ICD-10-AM) codes V100 to V199, and were read by experienced clinicians to extract details about crash mechanisms and locations. The focus was on the preventable aspects of the crash, rather than injury details. Newcastle and Lake Macquarie LGAs were selected because these councils are actively trying to improve cycling safety. Patients were selected for telephone interview if they had been riding on a road, footpath or cycleway, or their location was undetermined, and they were over 10 years of age. Patients were excluded if they were riding in bushland, jumping, or taking part in a competition. 


\section{Results}

We reviewed 181 records, in which 85 people were injured on a road or cycleway, and 42 were injured offroad; location could not be determined for 54 people. There were 145 males and 36 females, with an average age of 34 years; 21 people were aged less than 10 years. Length of hospital stay ranged from 0 to 26 days, with a median stay of 2 days. Two people died. A total of 54 events (29.7\%) had latitude and longitude recorded by an ambulance, and 11 more had sufficient detail to be geocoded.

We could extract a story about what happened for 168 admissions: 25 involved some interaction with a car (three involved an opening car door). Overall, the hospital record did not give enough detail to understand how the crashes could have been prevented, or sufficient location details to report crash incidence by LGA.

Of 79 patients selected for interview, 60 consented: 48 male and 12 female, including 10 children aged 10 or older, and five aged over 65. Participating cyclists were keen to talk and appreciated the aims of the research. Telephone interviewers used Google Street View during the calls to better understand the road environment at the crash site.

Nine interviews identified specific safety hazard locations that could be passed on to local and state authorities for remedial attention. Details of crashes relating to poor road or track surface, engineered conflict at squeeze points or tight corners on cycleways, dangerous road furniture, and poorly designed kerb ramps were taken up with councils and road managers. Environmental causes of crashes identified from interviews are shown in Table 1.

Table 1. Crashes with environmental causes identified from interviews

\begin{tabular}{lc}
\hline Cause of crash & $\begin{array}{c}\text { Number of } \\
\text { crashes }\end{array}$ \\
\hline Moving vehicle - failed to see & 14 \\
Poor road or track surface & 5 \\
Poorly designed kerb ramps & 4 \\
Engineered conflict at squeeze points or tight & 3 \\
corners on cycleways & 2 \\
Dangerous road furniture & 2 \\
Multilane roundabouts & 1 \\
Malicious assault with a motor vehicle & \\
\hline
\end{tabular}

Note: Crashes with no environmental cause are not included in this table.

The time taken to complete this study, not including approvals, was 42 hours - 17 hours to review admission records, 15 hours for interviews, and approximately 10 hours of organising time.

\section{Discussion}

Hospital admission records on their own cannot be used for surveillance of the number of cyclist injuries at the local government level, because the hospital record does not contain adequate location detail.

A moving vehicle was involved in 14 of 60 (23\%) events for which we interviewed the patient. This indicates that the public perception that cars make cycling dangerous is only part of the story.

Along with nine specific hazard locations, we identified the following remediable environmental factors:

- Poor choice of paint for pedestrian crossings that becomes slippery when wet

- Commonly used cycle-unfriendly design of driveway ramps, which end in a $50 \mathrm{~mm}$ vertical drop

- Double-lane roundabouts, which should be recognised as dangerous for cyclists and avoided wherever possible.

Factors that could prevent crashes with motor vehicles include:

- Cyclists wearing high-visibility vests or using a flashing light on the front of their bike, even during the day; however, one crash with a motor vehicle in this study occurred despite the use of a very bright front light

- Motorists leaving adequate space for cyclists; this could be encouraged by specific education during driver training and licensing.

\section{Conclusion}

This method of using hospital admissions and telephone follow-up to identify cycling safety issues is feasible, efficient and yields information of value to local government. A crash involving a bicycle is an event of public health importance - lack of safety on the road inhibits widespread adoption of cycling for transport, which would bring substantial health benefits through increased physical activity. We propose that, in the age of noncommunicable diseases, bicycle injury crashes should be notifiable health events, just as reporting of Salmonella cases has been of benefit in the age of public health through sanitation. Results of this study have been presented to local government, and several environmental hazards have been listed for remediation. The method could be generalised to the patients of any hospital where the community wished to make cycling safer.

\section{Competing interests}

None declared 


\section{Author contributions}

BE conceived the project and did file reviews, interviews, and wrote the report. TC helped design the project, did file reviews and interviews, and edited the report.

\section{References}

1. Yang X, Telama R, Hirvensalo M, Tammelin T, Viikari JSA, Raitakari OT. Active commuting from youth to adulthood and as a predictor of physical activity in early midlife: the young Finns Study. Prev Med. 2014;59:5-11.
2. Rosenkranz KM, Sheridan RL. Trauma to adult bicyclists: a growing problem in the urban environment. Injury. 2003;34(11):825-9.

3. De Rome L, Boufous S, Senserrick T, Richardson D, Ivers R. The pedal study: factors associated with bicycle crashes and injury severity in the ACT. Final report July 2011. Sydney: The George Institute for Global Health; 2011 [cited 2015 May 27]. Available from: www.roadsafetytrust.org.au/c/rtt?a=sendfile\&ft=p\&f id $=1330472150$

\section{Copyright: (c) (i) (2)}

(C) 2015 Ewald and Cowan. This article is licensed under the Creative Commons Attribution-NonCommercial-ShareAlike 4.0 International Licence, which allows others to redistribute, adapt and share this work non-commercially provided they attribute the work and any adapted version of it is distributed under the same Creative Commons licence terms. See: www.creativecommons.org/licenses/by-nc-sa/4.0/ 